\title{
BURNOUT AND HEALTH RELATED QUALITY OF LIFE AMONG RESIDENT PHYSICIANS IN ZAGAZIG UNIVERSITY HOSPITALS
}

\author{
By \\ AbdAllah AM and El-Hawy LL \\ Department of Family Medicine, Department of Community, Environmental and Occupational Medicine, \\ Faculty of Medicine, Zagazig University. \\ AbdAllah AM:dr.amanymohammed@gmail.com_El-HawyLL:lamiaa102elhawy@yahoo.com
}

\begin{abstract}
Introduction: Burnout syndrome (BO) is an increasingly serious problem among physicians. It is highly prevalent in health care settings .The impact of burnout not only affects physicians but extends to their patients if the quality of medical care delivered had been affected. Quality of life (QoL) is a multidimensional concept affected by all life aspects of individuals. Aim of work: To assess the prevalence of BO syndrome among resident physicians working in Zagazig University hospitals, to assess their quality of life (QoL), to identify some risks factors of BO and to study the effect of BO on QoL. Materials and methods: A cross sectional study was conducted at Zagazig University hospitals on one hundred sixty eight resident physicians. Socio-demographic characteristics, Maslach BO scale and 12-Item Short-Form Survey Instrument version 2 (SF-12v2) questionnaires were collected from studied physicians. Results: the largest percentage of studied physicians had emotional exhaustion (EE), depersonalization (DP), loss of personal accomplishment (PA) and high total BO score (53, 64.3, 75 and $67.3 \%$ ) respectively. There are significant differences between gender, social class, marital status, department and total BO score. Physicians with higher BO reported lower QoL score. Physicians working in surgical departments reported significantly lower score in each domain. Male gender and single physicians reported significantly lower Mental Component Summary score (MCS) of QoL. Conclusion: All resident physicians suffered from moderate to high BO syndrome. Being male resident, single and working in surgical departments were the predictors of BO. Residents working in medical departments had better physical and mental QoL.
\end{abstract}

Keywords: Burnout, Quality of life, Resident physician, Maslach Burnout Inventory (MBI), Physical Component Summary score (PCS) and Mental Component Summary score (MCS). 


\section{Introduction}

Burnout syndrome (BO) is recognized as the body's response to the failure of the coping strategies that individuals typically utilize to manage work stress (Marin and Compryo, 2010). BO is described as emotional exhaustion which results in depersonalization and decreased personal accomplishment at work. The emotionally exhausted clinician is overwhelmed by work to the point of feeling fatigued, unable to meet the job demands, and unable to participate with others. The burned out clinician may get a sense of work detachment and consider people, especially patients, as objects. Fatigue and detachment merge such that clinicians no longer feel effective at work (Lyndon, 2016).

Burnout is a growing problem among medical staff and is highly prevalent in health-care settings. It is related to hard working conditions and perception of dissatisfaction with work (De Oliveira et al., 2011).

BO has been linked with negative workplace activities such as absenteeism, sick leaves, premature retirement, low morale, increases in smoking and coffee consumption, and workplace accidents (Lundgren-Nilsson et al., 2012). The impact of BO not only affects the suffering physicians but extends to their patients if the quality of medical care delivered is undermined (Abdulghafour et al., 2011). Health not only means the absence of disease but also includes physical, mental, and social well-being (WHO, 2015).

Quality of life (QOL) is a fundamental clinical health assessment tool. It is also a multidimensional theory affected by all life features of individuals. QOL is the appraisal of the living environment and the gratification of individuals in their environment. QOL pools the expressed satisfaction and objective descriptions (Felce and Perry, 1995).

\section{Aim of work}

To assess the prevalence of burnout (BO) syndrome among resident physicians working in Zagazig University hospitals, to assess their quality of life (QoL), to identify some risks factors of $\mathrm{BO}$ and to study the effect of BO on QoL.

\section{Materials and methods}

Study design: It is a cross sectional study.

Place and duration of the study: The study was done in Zagazig 
University Hospitals during the period from the 1st of January 2017 to the end April of 2018.

\section{Study sample:}

By assuming, prevalence of burnout among physicians was $66.5 \%$ (Abdo et al., 2015) and total population of our study (274) at 95\% CI and power $80 \%$, the sample was (153) and with $10 \%$ non-response rate, the sample was (168).It is calculated by Epi-info (Epidemiological Information Package) software version 6.04. A stratified random sample was drawn from resident physicians working at Zagazig University hospitals. At first Zagazig University hospitals departments are classified into medical and surgical departments and then, a representative sample will be drawn from both departments, taking into consideration proportion allocation.

\section{Study methods:}

1- The study was done through using interview questionnaires.

Socio-demographic characteristics: using the updated scale for assessing the socio-economic status (El- Gillany et al., 2012) after its modification. Sociodemographic score less than 50\% (low), score $50 \%$ - less than $75 \%$ (middle) and score $75 \%$ and more (high).

\section{2- Maslach Burnout Inventory} (MBI): it is used to measure BO due to its high reliability and validity. The questionnaire was translated into Arabic by a professional translator. We apply the questionnaire two times in Arabic and English, we compare mean and standard deviation of the same subject using paired $t$ test with no significant difference. So that the Arabic translation was valid to be used instead. Internal consistency was done with cronbach`s alpha coefficient (Maslach et al., 1996).It consists of the 22 items with Likert scale ranged from (0) never to (6) every day. These items represent the three dimensions; EE (Emotional Exhaustion), DP (Depersonalization) and PA (Loss of Personal Accomplishment). For each dimension: score low, moderate or high. Depending on the number of dimensions' scored, the degree of burnout can be described as; low if only one dimension is touched, moderate if two dimensions are concerned or high if all dimensions are touched ((Maslach et al., 1996).

3-12-Item Short-Form Survey Instrument version 2 (SF-12v2): it is frequently used to monitor QoL. It 
measures 8 characteristics of functional health status: physical functioning, role limitations resulting from physical health problems, bodily pain, general health, vitality (energy and fatigue), social functioning, role limitations resulting from emotional problems, and mental health (psychological distress and psychological well-being): Physical Component Summary score (PCS) and Mental Component Summary score (MCS).Higher scores represent better health (Larson et al., 2008).

\section{Data collection}

A Pilot study was carried out on 15 resident physicians who were not included in the study to test the contents of the prepared questionnaire and time. Then physicians included in the study were interviewed and asked to fill in the study questionnaires

\section{Consent}

An informed verbal consent was taken from all physicians participating in the study after explaining title and study objectives ; confidentiality of data was assured.

\section{Ethical approval}

Approval from the Institutional
Review Board (IRB) for Medical Research Ethics, Zagazig University, Faculty of Medicine was obtained prior to implementation of the study. An official permission from Zagazig University, Faculty of Medicine was taken to Zagazig University hospitals departments. The title and objectives of this study was explained to them to ensure their cooperation.

\section{Data management}

The collected data was analyzed and computerized using Statistical Package of Social Services version 20 for windows (SPSS Inc., Chicago, IL, USA). Normality of continuous variables was checked by ShapiroWilk test, and was expressed as (Mean $\pm \mathrm{SD}$ ). The categorical variables were expressed as a number (percentage). Independent sample $\mathrm{t}$ test was used to compare between two groups of normally distributed data. Percent of categorical variables were compared using Pearson's Chi-square test or Fisher's exact test when was appropriate. Logistic regression analysis used to determinate the predictors of $\mathrm{BO}$. All tests were two sided and $\mathrm{p}$-value $<0.05$ was considered significant. 


\section{Results}

\section{Demographic characteristics of the studied physicians:}

The largest percentage of the studied participants were male $(58.3 \%)$, of middle social class $(60.7 \%)$, working in medical departments $(54.2 \%)$, working for more than two years ago (45.8\%) and married (54.8\%). Their ages ranged from 25 to 29 years old with $($ Mean \pm SD $)=27.46(0.82)$.

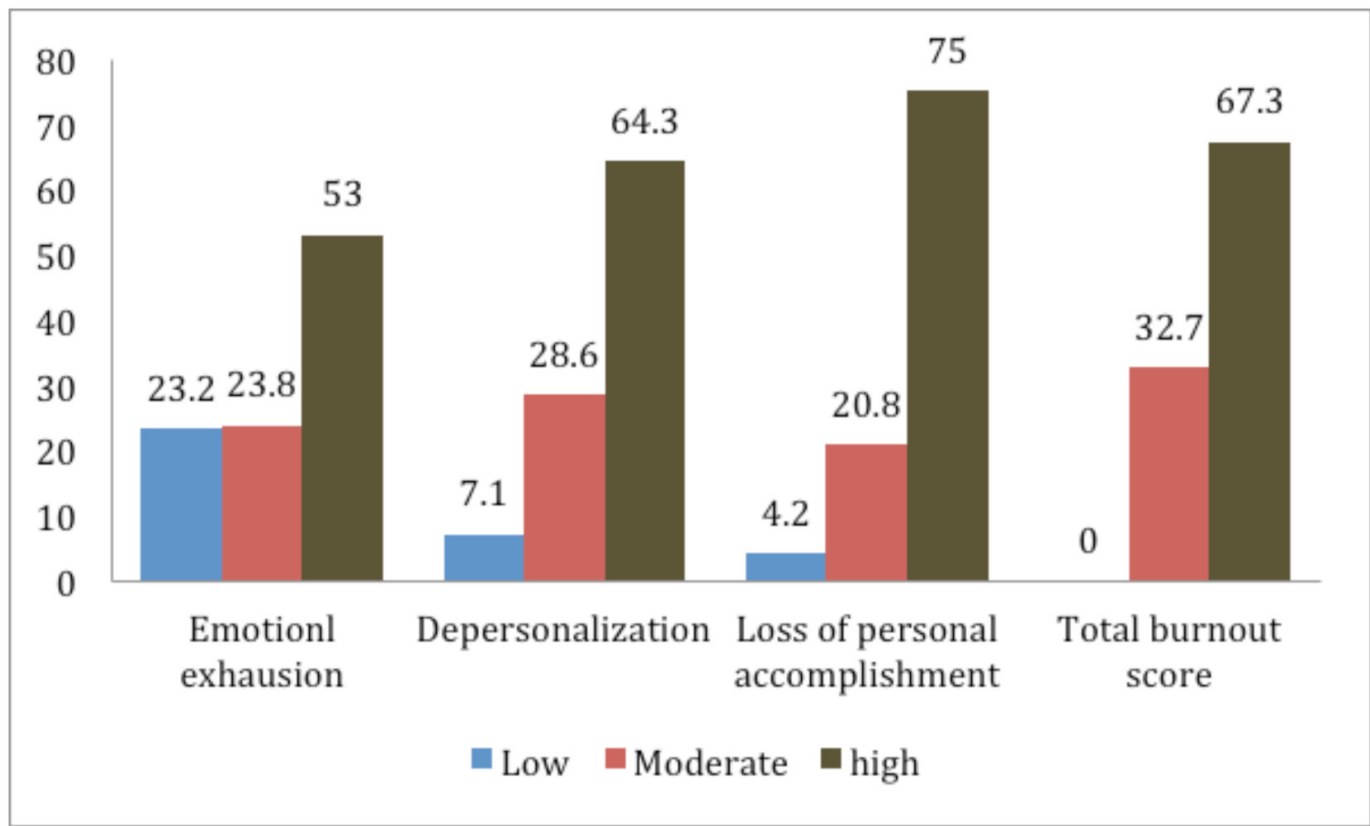

Figure (1) : Combined bar chart showing burnout domains among the studied physicians.

Figure 1 showed that the largest percentage of physicians had high EE, DP, loss of PA and total burnout score $(53,64.3,75$ and $67.3 \%)$ respectively. No one of physicians reported low total burnout score. 
Table (1): Burnout among the studied physicians in relation to working departments.

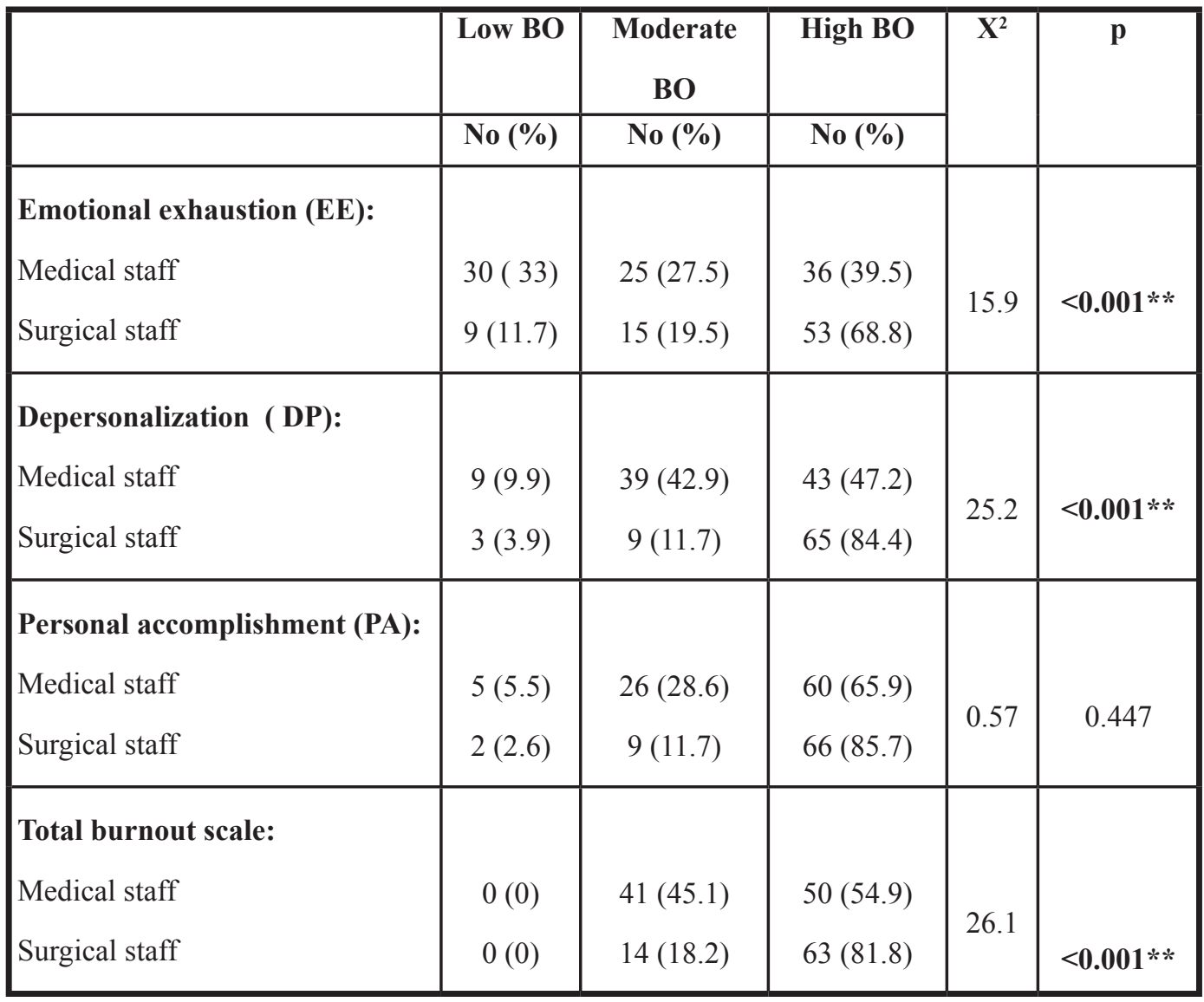

BO: Burnout

**: Highly statistically significant

Table 1 showed that there was statistically significant difference between type of departments where residents worked and EE, DP, PA and total burnout scale. Physicians worked in surgical departments reported higher EE, DP, loss of PA and total burnout score. 
Table (2): Relation between demographic, work related characteristics and burnout among the studied physicians.

\begin{tabular}{|c|c|c|c|c|}
\hline & Moderate BO & High BO & $\mathbf{X}^{2}$ & p \\
\hline & No $(\%)$ & No $(\%)$ & & \\
\hline \multicolumn{5}{|l|}{ Gender: } \\
\hline Male & $16(29.1)$ & $82(76.2)$ & 28.76 & $<0.001 * *$ \\
\hline Female & $39(70.9)$ & $31(27.4)$ & & \\
\hline \multicolumn{5}{|l|}{ Age ( years): } \\
\hline Mean \pm SD & $27.49 \pm 0.63$ & $27.44 \pm 0.9$ & $\mathrm{t}(0.40)$ & 0.687 \\
\hline Range & $25-28$ & $25-29$ & & \\
\hline \multicolumn{5}{|l|}{ Marital status: } \\
\hline Single & $14(25.5)$ & $55(48.7)$ & 11.32 & $0.003 *$ \\
\hline Married & $36(65.5)$ & $56(49.6)$ & & \\
\hline Divorced & $5(9.1)$ & $2(1.8)$ & & \\
\hline \multicolumn{5}{|l|}{ Social class: } \\
\hline Low & $6(10.9)$ & $43(38.1)$ & 13.5 & $<0.001 * *$ \\
\hline Middle & $41(74.5)$ & $61(54)$ & & \\
\hline High & $8(14.5)$ & $9(8)$ & & \\
\hline \multicolumn{5}{|l|}{ Years of work: } \\
\hline$<$ one year & $10(18.2)$ & $21(18.6)$ & 4.169 & 0.124 \\
\hline 1-2 years & $23(41.8)$ & $27(18.6)$ & & \\
\hline$>2$ years & $22(40)$ & $55(32.7)$ & & \\
\hline \multicolumn{5}{|l|}{ Departments: } \\
\hline Medical & $41(74.5)$ & $50(44.2)$ & 13.678 & $<0.001 * *$ \\
\hline Surgical & $14(25.5)$ & $63(55.8)$ & & \\
\hline
\end{tabular}

Table 2 showed that there was statistically significant differences between genders, social class, marital status, departments and total burnout score where male, low social class, single and surgical staff residents reported the higher burnout score. 
Quality of life among the studied physicians: Physical Component Summary score (PCS) of studied physicians was $39.35( \pm 4.31)$ while Mental Component Summary score (MCS) was33.34 $( \pm 5.17)$. On assessing relation between QoL among the studied physicians and their reported burnout, PCS mean score was (39.95 \pm 3.59$)$ in physicians reported moderate burnout and (39.11 \pm 4.55$)$ in those with high burnout with non-significant difference $(\mathrm{p}=0.234)$. MCS mean score was $(34.8 \pm 4.5)$ among physicians reported moderate burnout and (32.62 \pm 5.34$)$ in those with high burnout with significant difference $(\mathrm{p}=0.01)$. (Data are not tabulated).

Table (3): Relation between demographic, work related characteristics, burnout and Quality of life among the studied physicians.

\begin{tabular}{|c|c|c|c|c|c|c|}
\hline & $\begin{array}{c}\text { PCS } \\
\text { Mean } \pm \text { SD }\end{array}$ & Test & $\mathbf{p}$ & $\begin{array}{c}\text { MCS } \\
\text { Mean } \pm \mathrm{SD}\end{array}$ & Test & p \\
\hline $\begin{array}{l}\text { Gender: } \\
\text { Male } \\
\text { Female }\end{array}$ & $\begin{array}{l}39.26 \pm 4.23 \\
39.57 \pm 4.34\end{array}$ & $-0.46^{¥}$ & 0.64 & $\begin{array}{l}32.42 \pm 5.08 \\
34.62 \pm 5.04\end{array}$ & $-2.78^{¥}$ & $0.006 * *$ \\
\hline $\begin{array}{l}\text { SES: } \\
\text { Low } \\
\text { Middle } \\
\text { High }\end{array}$ & $\begin{array}{l}39.76 \pm 4.3 \\
38.9 \pm 4.31 \\
41.22 \pm 3.4\end{array}$ & $2.44^{\#}$ & 0.09 & $\begin{array}{c}32.33 \pm 5.42 \\
33.51 \pm 5.2 \\
35.19 \pm 3.63\end{array}$ & $2.11 \#$ & 0.124 \\
\hline $\begin{array}{l}\text { Marital status: } \\
\text { Single } \\
\text { Married } \\
\text { Divorced }\end{array}$ & $\begin{array}{l}39.45 \pm 4.27 \\
39.07 \pm 4.25 \\
42.98 \pm 2.96\end{array}$ & $2.81^{\#}$ & 0.06 & $\begin{array}{l}31.37 \pm 4.88 \\
34.78 \pm 5.05 \\
33.79 \pm 3.16\end{array}$ & $9.51^{\#}$ & $0.001^{* *}$ \\
\hline $\begin{array}{l}\text { Years of work: } \\
<\text { one year } \\
1 \text { to } 2 \text { years } \\
>2 \text { years }\end{array}$ & $\begin{array}{l}40.83 \pm 4.91 \\
39.32 \pm 3.68 \\
38.86 \pm 4.34\end{array}$ & $2.39^{\#}$ & 0.09 & $\begin{array}{c}33.31 \pm 4.6 \\
33.2 \pm 5.86 \\
33.45 \pm 4.87\end{array}$ & $0.04^{\#}$ & 0.961 \\
\hline $\begin{array}{l}\text { Burn out ( BO) } \\
\text { Moderate } \\
\text { High }\end{array}$ & $\begin{array}{l}39.95 \pm 3.59 \\
39.11 \pm 4.55\end{array}$ & $1.196^{¥}$ & 0.234 & $\begin{array}{c}34.8 \pm 4.5 \\
32.62 \pm 5.34\end{array}$ & $2.61^{¥}$ & $0.01 *$ \\
\hline
\end{tabular}

$¥:$ Independent sample t test

*: Statistically significant

PCS: Physical Component Summary score
\# : one way ANOVA

SES: socioeconomic score **: Highly statistically significant MCS: Mental Component Summary score 
Table 3 showed that there was a statistically significant difference between gender, marital status, level of BO and MCS, while single, male and high BO had the lowest scores.

Table (4): QoLdomains among the studied physicians in relation to departments.

\begin{tabular}{|l|c|c|c|c|}
\hline \multicolumn{1}{|c|}{ QoL domains } & Medical staff & Surgical staff & $\mathbf{t}$ & $\mathbf{p}$ \\
\cline { 2 - 5 } & Mean \pm SD & Mean \pm SD & & \\
\hline Physical functioning & $42.5 \pm 7.96$ & $34.71 \pm 10.2$ & 5.439 & $<\mathbf{0 . 0 0 1 * *}$ \\
\hline Role physical & $38.19 \pm 3.81$ & $33.66 \pm 3.63$ & 7.840 & $<\mathbf{0 . 0 0 1 * *}$ \\
\hline Body pain & $35.17 \pm 7.58$ & $33.22 \pm 4.97$ & 1.917 & 0.057 \\
\hline General health & $38.53 \pm 9.72$ & $42.81 \pm 8.68$ & -2.982 & $\mathbf{0 . 0 0 3 * *}$ \\
\hline Vitality & $45.98 \pm 8.3$ & $46.18 \pm 7.31$ & -0.165 & 0.869 \\
\hline Social functioning & $29.71 \pm 6.93$ & $26.41 \pm 4.77$ & 3.644 & $<\mathbf{0 . 0 0 1} * *$ \\
\hline Role emotional & $32.36 \pm 7.92$ & $27.9 \pm 4.58$ & 4.526 & $<\mathbf{0 . 0 0 1 * *}$ \\
\hline Mental health & $38.48 \pm 4.73$ & $33.51 \pm 6.27$ & 5.856 & $<\mathbf{0 . 0 0 1 * *}$ \\
\hline PCS & $40.63 \pm 4.24$ & $37.23 \pm 5.32$ & 5.854 & $<\mathbf{0 . 0 0 1 * *}$ \\
\hline MCS & $34.54 \pm 6.65$ & $31.33 \pm 6.06$ & 3.246 & $<\mathbf{0 . 0 0 1 * *}$ \\
\hline
\end{tabular}

PCS: Physical Component Summary score

MCS: Mental Component Summary score

**: Highly statistically significant

Table 4 showed that there was a significant difference between physicians working in medical and surgical departments and physical functioning, role limitations resulting from physical health problems, general health, social functioning and role limitations resulting from emotional health problems, mental health, PCS and MCS domains of QoL. Physicians working in surgical departments reported lower score in each domain.

Predictors of high burnout among the studied physicians: Multivariate analysis by linear regression revealed that being male (OR 4.638, $\mathrm{p}<0.001$ ), working in surgical departments (OR 1.871, p 0.132), and single (OR 1.319, $\mathrm{p}=0.51$ ) were the predictors of burnout (Results are not tabulated). 


\section{Discussion}

Burnout (BO) syndrome is defined as losing interest for work (emotional exhaustion), viewing people as objects (depersonalization), and feeling that work is no longer essential (low personal accomplishment). This situation is as well connected to negative physiological, cognitive, psychological and behavioral expressions. BO syndrome is not a sign of brittleness, mental disorder or failure to cope with life so; it can be treated, overcome, and prevented (Shanafelt et al., 2003).

Despite the physicians' work can be gratifying, factors comprising worklife imbalance, workload, and distress rooted from complaints and shortage of mutuality in contacts with patients and coworkers may reduce job satisfaction and consequently increase the hazards of BO (Biksegn et al., 2016)

This study was designed to measure the prevalence of $\mathrm{BO}$ among resident physicians working in Zagazig University hospitals, to identify some of its determinants and its effects on health related quality of life among the studied physicians. The prevalence of burnout among physicians in the current study was very high (100)\%. Moderate degree of BO was present in about one third $(32.7 \%)$ of our participants while severe form of $\mathrm{BO}$ was present in the rest two thirds of them (67.3\%) (Figure1). This can be accredited to understaffing along with overburdened hospital wards including loaded schedules, frequent shifts, lack of resources and lack of financial appreciation.

In Egypt, various studies described higher prevalence of burnout among health care workers than ours, $66 \%$ considered as having a moderate level of burnout in Tanta (Abdo et al., 2015) and $63.1 \%$ in Suez Canal(Yousef et al., 2006) . The results of our study was similar to that detected by Farahat et al. (2017), who found that approximately $66.7 \%$ of the general practitioners (GPs) had high burnout, whereas it is present only in $26.7 \%$ of specialists. On the other hand, a study done in Qatar found that $12.6 \%$ of the responders were experiencing $\mathrm{BO}$ without mentioning the degree (Abdulla et al., 2011).

Prior European studies including medical and paramedical crews, specified widely diverse $\mathrm{BO}$ rates ranging from 15-82\% (Hyman et al., 2011; Roth et al., 2011). French and Portuguese studies showed high levels of burnout in ICU workers; 50\% and $31 \%$ respectively (Teixeira et al., 2013). 
Others reported; $32.8 \%$ and $47 \%$ in two different nationwide French studies (Embriaco et al., 2007; Poncet et al., 2007) and 28\% in Switzerland( Merlani et al., 2011). Studies done in USA found that the prevalence of burnout among emergency physicians ranged from 25-60\% (Cydulka et al., 2008) and more than $90 \%$ in Canada (Wallace et al., 2009).

Different reported rates of $\mathrm{BO}$ can be probably accredited to diverse scales used in measuring BO, type of medical sector studied, culture discrepancy; including patients' attitudes, the nature of the health system in different countries. High EE was reported in more than half of our participants $(53 \%)$ and about two thirds of them showed high DP scale while three quarters of them showed highly reduced personal accomplishment (Figure 1).

Our study revealed that $68.8 \%$ of resident physicians working in surgical departments experienced high emotional exhaustion compared to $39.5 \%$ of their fellows working in medical departments. About $85 \%$ and $86 \%$ of surgical staff reported high DP and loss of accomplishment respectively compared to $47.2 \%$ and $65.9 \%$ of medical staff physicians (Table 1) .On comparing site of work whether medical or surgical departments, it was found that physicians in surgical department reported significantly higher burnout than medical staff members (Table $2)$. This can be explained by higher work hours and work responsibilities and more exposure to emergency and life striving patients in surgical departments. Embriacoet al. (2007), Poncet et al. (2007) and Teixeira et al. (2013) reported an increased BO among those who had dealt with dying patients or who had participated in decisions of life-maintaining treatment.

Our work showed that high BO was statistically significantly more prevalent among males (Table 2). This can be attributed to that male is overburdened by work in both governmental and private hospitals to achieve accepted financial income and difficulty in getting days off. Shanafelt et al. (2002) and Merlani et al. (2011) agreed with us regarding this finding.

Other study disagreed with us as they reported that women had nonsignificant higher burnout (Biksegn et al., 2016). But Terrones et al (2016) and Teixeira et al. (2013) reported that women had significantly higher BO.

Regarding marital status, more than 
half of single physicians had severe BO compared to one quarter of single reported moderate $\mathrm{BO}$ (Table 2). Other studies showed that being single and childless might be associated with a higher risk of burnout (Chen and McMurray, 2001, Merlani et al., 2011 and Teixeira et al., 2013). Martini et al., 2004 showed that $65.2 \%$ of single, divorced, or unmarried residents met the criteria for burnout compared with $40.0 \%$ of married individuals. Other studies report no correlation between marriage and burnout (Shanafelt et al., 2002).

Mean age of physicians with high BO was 27.44 years which was nonsignificantly lower than those with moderate BO (Table 2). In agreement with this finding, Chen and McMurray, 2001, believed that younger individuals may be more sensitive to job burnout. Woodside et al. (2008) evaluated the association between age and burnout, and showed an inverse correlation between DP scores and age of residents. However, other studies showed no significant correlation between age and burnout (Prins et al., 2007).

The present study revealed that years of work non-significantly affect presence of burnout among physicians
(Table 2). This can be explained that while junior physicians are stressed by new job and still unaccustomed to long work hours and emergent cases also senior physicians overwhelmed by teaching duties, postgraduate exams and higher work responsibilities. Previous studies have revealed different findings regarding the association between burnout level and years of working experience. Some results have indicated that experienced physicians became more skilled and committed to their work, therefore staying more calm and controlled when facing unpredictable situations and feeling more successful in their profession, resulting in the identification of a decreased level of burnout (Taycan et al., 2006).

In the current work, Multivariate analysis of factors affecting $\mathrm{BO}$ included being male physician, single and surgical department residents were important predictors for burnout in which being male significantly increase likelihood of BO by 6 times ,sleep deprivation increase BO by about 5 times ( Results are not tabulated). Merlani et al. (2011) showed that being a male, having no children, and being less than 40 years old was each independently associated with high BO. 
Being a female, childless, and not living alone were independently associated with high stress. On the other hand, Abdo et al. (2015) concluded that age, supervision, work activities and load, frequent exposure to work related violence and years of experience were significant predictors of BO. It is reported that age, the perception of stressful job, poor salary, and sector type predicted high BO level (Pavlakis et al., 2010).

In a study done by (Al-Shoraian et al., 2011) in Kuwait to assess burnout among family physicians and general practitioners, working in family health center (OR 0.1) and marital status (OR 3.74) were the predictors of burnout.

On comparing different QoL domains among both medical and surgical resident physicians, surgical physicians had significantly lower physical functioning, role physical, social functioning, role emotional, mental health, physical and mental component summary (MCS) scores (Table 4). On the other hand, they had significantly higher vitality and general health. Female physicians had significantly higher mental QoL summary score and non-significantly higher physical component summary
(PCS) scores (Table 3). This can be explained that male physicians had higher burnout, hence lower QoL. Single physicians had significant lower mental QoL score which is in agreement that they had higher BO.

Social class and years of work non-significantly affect PCS and MCS (Table 3). On assessing relation between BO and QoL in both medical and surgical teams, those with higher BO had significantly lower PCS and MCS which were also more significantly lower among surgical staff. This finding supports our hypothesis that BO significantly impairs QoL.

In a study done by Fernández-Prada et al., 2014 to assess QoL among resident physicians working in emergency departments, female had worst QoL compared to male in contrast with our finding. Work-related burnout was not found to be associated with well-being, after adjustment for other variables (Kassam et al., 2015). It is well known that residents experience various types of stress during training, and that such stress factors can cause harmful effects, impacting quality of patient care.

High levels of burnout lead to a significant deterioration in the mental QoL and non-significant deterioration 
in physical QoL physically and psychologically (Table 3). This is in accordance with a study performed in Spain and India (Uner-Soler et al., 2013).

\section{Conclusion and recommendations:}

All resident physicians suffered from moderate to high $\mathrm{BO}$ syndrome. Being male, single and working in surgical departments were the predictors of BO. Residents working in medical departments had better physical and mental QoL. We recommend that longitudinal studies should be done to elucidate the incriminating causes of $\mathrm{BO}$; pre-employment health education programs for prevention of $\mathrm{BO}$; and periodic screening for early detection and management of $\mathrm{BO}$ among resident physicians.

\section{Limitations of the study:}

This study had some limitations as it is applied in single center, including only resident physicians and lack of objective assessment of quality of care provided by them.

\section{Conflicts of interest}

None.

\section{Funding}

Self-funded.

\section{References}

1. Abdo S, El-Sallamy RM, El-Sherbiny AAM and Kabbash I (2015): Burnout among physicians and nursing staff working in the emergency hospital of University of Tanta, Egypt. EMHJ; 21: 785:94

2. Abdulghafour YA, Bo-hamrab AM, Al-Randic MS and Shazly M (2011): Burnout syndrome among physicians working in primary health care centers in Kuwait. Alexandria Journal; 47: 351-357. DOI: 10.1016/j.ajme.2011.08.004

3. Abdulla L, Al-Qahtani DM and Al-Kuwari MG (2011): Prevalence and determinants of burnout syndrome among primary healthcare physicians in Qatar. South African Family Practice Journal; 53(4):380-3.

4. Al-Shoraian GMJ,Hussain N, AlajmiMF, Kamel MI and El-Shazly MK (2011): Burnout among family and general practitioners. Alexandria $\mathbf{J}$ Med; 47:359-64.

5. doi: 10.1016/j.ajme.2011.10.005.

6. Barutcu E and Serinlcan C (2008): Burnout as a significant problem in today's world and a study in Denizli. Ege Acad Rev; 8: 541-61.

7. Biksegn A, Kenfe T, Matiwos S, and Eshetu G (2016): Burnout Status at Work among Health Care Professionals in a Tertiary Hospital. Ethiop J Health Sci; 26 (2):101-8.

8. Celebi E (2014): Burnout among Psychiatric Nurses and Associated Factors. Int J Basic Sci Appl Res; 3:765-71.

9. Chen S and McMurray A (2001): Burnout in intensive care nurses. J Nurs Res; 9(5):152-64.

10. Cydulka RK and Korte R (2008): Career satisfaction in emergency medicine: the ABEM Longitudinal Study of Emergency Physicians. Ann Emerg Med; 51(6):714-722.e1.

11. De Oliveira GS, Ahmad S, Stock MC, Harter RL, Almeida MD, et al. (2011): High incidence of burnout in academic chairpersons of anesthesiology: should we be taking better care of our leaders? Anesthesiology; 114(1):181-93. PMID: 21178674. 
12. Demir A, Ulusoy M and Ulusoy M (2003): Investigation of factors influencing burnout levels in the professional and private lives of nurses. Int J Nurs Stud; 40:807-27.

13. El-Gilany A, El-Wehady A, and El-Wasify $M$ (2012). Updating and validation of the socioeconomic status scale for health research in Egypt. East Mediterr Health J; 18(9):962-8.

14. Embriaco N, Azoulay E, Barrau K, Kentish N, Pochard F et al. (2007) : High level of burnout in intensivists: prevalence and associated factors. Am J Respir Crit Care Med; 175: 686-92.

15. Farahat TM, Hegazy NN and Mohamed DH (2017): Burnout and quality of life among physicians in primary healthcare facilities in Egypt: a cross-sectional study. Menoufia Medical journal; 30 (3): 789-93. doi: 10.4103/ mmj.mmj_442_16

16. Felce D and Perry J (1995): Quality of life: Its definition and measurement. Res Dev Disabil; 16(1):51-74. doi: 10.1016/08914222(94)00028-8.

17. Fernández-Prada M, González-Cabrera J, Torres G F, Iribar-Ibabe C and María Peinado J (2014): Gender influence on health related quality of life among resident physicians working in an emergency department. Rev Med Chil; 142(2):193-8. doi: 10.4067/S003498872014000200007.

18. Galván ME, Vassallo JC, Rodríguez SP, Otero P, Montonati MM, et al. (2012): Professional burnout in pediatric intensive care units in Argentina. Arch Argent Pediatr; 110:466-73.

19. Hyman SA, Michaels DR, Berry JM, Schildcrout JS, Mercaldo ND, et al. (2011): Risk of burnout in perioperative clinicians: a survey study and literature review. Anesthesiology; 114(1):194204.

20. Kassam A, Horton J, Shoimer I, and Patten S (2015): Predictors of Well-Being in Resident Physicians: A Descriptive and Psychometric Study. J Grad Med Educ; 7(1): 70-74.doi: 10.4300/JGME-D-14-00022.1

21. Larson CO, Schlundt D, Patel K, Beard
K, Hargreaves M, et al .(2008): Validity of the SF-12 for Use in a Low-Income African American Community-Based Research Initiative (REACH 2010). Prev Chronic Dis; 5(2): A44

22. Lundgren-Nilsson A, Jonsdottir IH, Pallant J and Ahl- borg Jr (2012): Internal construct validity of the shi-rom-melamed burnout questionnaire (SMBQ). BMC Public Health, 12, 1. doi:10.1186/1471-2458-12-1

23. Lyndon A (2016): Burnout among Health Professionals and Its Effect on Patient Safety. Annual perspectives2015. PSNet. Available at: https://psnet.ahrq.gov/perspectives/ perspective/190/burnout-among-healthprofessionals-and-its-effect-on-patient-safety

24. Marin M and Campayo GA (2010): A newer and broader definition of burnout: Validation of the burnout clinical subtype questionnaire (BCSQ36). BMC Public Health;10:302. Available at: http://www.biomedcentral.com/14712458/10/302

25. Martini S, Arfken CL and Churchill A (2004): Burnout comparison among residents in different Medical Specialties; 28(3):240-2.

26. Maslach C, Jackson SE and Leiter MP (1996): Maslach Burnout Inventory manual. 3rd ed. Palo Alto (CA): Consulting Psychologist Press. Available at : https://www.researchgate. net/publication/277816643_The_Maslach_ Burnout_Inventory_Manual

27. Merlani $P$, Verdon $M$, Businger A, Domenighetti G, Pargger H, et al. (2011): Burnout in ICU caregivers: a multicenter study of factors associated to centers. Am J Respir Crit Care Med ; 184:1140-6.

28. Pavlakis A, Raftopoulos V and Theodorou M (2010): Burnout syndrome in Cypriot physiotherapists: a national survey. BMC Health Serv Res; 10:63.

29. Poncet MC, Toullic P, Papazian L, KentishBarnes N, Timsit JF, et al. (2007): Burnout syndrome in critical care nursing staff. Am J Respir Crit Care Med; 175:698-704. 
30. Prins JT, Hoekstra-Weebers JE and van de Wiel HB (2007): Burnout among Dutch medical residents. Int J Behav Med; 14(3):119-25.

31. Roth M, Morrone K, Moody K, Kim M, Wang D, et al. (2011): Career burnout among pediatric oncologists. Pediatr Blood Cancer; 57(7):116873.

32. Shanafelt TD, Bradley KA, Wipf JE and Back AL (2002): Burnout and self-reported patient care in an internal medicine residency program. Ann Intern Med; 136:358-67.

33. Shanafelt TD, Sloan JA and Habermann TM (2003): The well being of physicians. Am J Med; 114(6):513-9.

34. Taycan O, Kutlu L, Cimen S and Aydın N (2006): Relation between sociodemographic characteristics depression and burnout levels of nurse working in university hospital. Anatolian J Psychiatry; 7:100-8.

35. Teixeira C, Ribeiro O, Fonseca AM and Carvalho AS (2013): Burnout in intensive care units: a consideration of the possible prevalence and frequency of new risk factors: a descriptive correlational multicentre study. BMC Anesthesiol ; 13:38.
36. Terrones-Rodríguez JF, Cisneros-Pérez V and Arreola-Rocha JJ (2016): Burnout syndrome in medical residents at the General Hospital of Durango, Mexico. Rev Med Inst Mex Seguro Soc; 54(2):242-8.

37. Uner-Soler R, Grau-Martin A, Font-Mayolas S, Gras ME, Bertran C, et al.( 2013): Burnout and quality of life among Spanish healthcare personnel. J Psychiatr Ment Health Nurs; 20:305-313.

38. Wallace JE, Lemaire JB, and Ghali WA (2009): Physician wellness: a missing quality indicator. Lancet; 374:1714-21.

39. WHO (2015): Definition of Health, Retrieved July 15, 2015. Available at: http://www.who. int/ trade/glossary/story046/en/

40. Woodside JR, Miller MN and Floyd MR (2008): Observations on burnout in family medicine and psychiatry residents. Acad Psych; 32(1):13-9.

41. Yousef IM, Hosny AO, Elsayed OI and Ali EG (2006): Burnout Syndrome among Resident Physician in Suez Canal University Hospital. Current Psychiatry Ain Shams University; 13(1):24-43. 